\title{
A PRODUÇÃO DE SENTIDOS NO BOOKTUBE: UMA ANÁLISE DE THE GREAT GATSBY
}

\author{
The Production of Meaning on Booktube: an Analysis of The Great Gatsby
}

\section{La producción de sentido en el booktube: analizando El Gran Gatsby}

Renata Prado Alves Silva

Professora dos cursos de Comunicação e de Design do Centro Universitário Estácio Juiz de Fora pradorenata@gmail.com

\section{Resumo}

O presente artigo pretende, através de vídeos de resenhas de obras literárias, analisar de que forma os conteúdos compartilhados pela comunidade booktube, no YouTube, revelam práticas polissêmicas de leitura. São investigados os relatos dos booktubers, registrados em seus vídeos, bem como as percepções e opiniões dos espectadores que interagem através da seção de comentários de cada um dos vídeos que compõem a amostra desta pesquisa. A análise proposta tem como foco um conjunto de vídeos relacionados ao livro The Great Gatsby, de F. Scott Fitzgerald.

Palavras-chave: Booktube. Produção de sentidos. YouTube.

\begin{abstract}
This article intends to analyze, through videos reviews of literary works, how the contents shared by the booktube community on YouTube reveal polysemic reading practices. The booktubers' reports recorded in their videos are analysed, as well as the perceptions and opinions of the viewers who interact through the comments section of each of the videos that make up the sample of this research. The analysis focuses on a set of videos related to the book The Great Gatsby, by F. Scott Fitzgerald.
\end{abstract}

Key words: Booktube. Production of meaning. YouTube.

\section{Resumen}

Este artículo pretende, a través de videos de reseñas de obras literarias, analizar cómo los contenidos compartidos por la comunidad booktube en YouTube revelan prácticas de lectura polisémica. Se investigan los informes de los booktubers grabados en sus videos, así como las percepciones y opiniones de los espectadores que interactúan a través de la sección de comentarios de cada uno de los videos que conforman la muestra de esta investigación. El análisis propuesto se centra en un conjunto de videos relacionados con el libro El Gran Gatsby, de F. Scott Fitzgerald.

Palabras clave: Booktube. Producción de significado. YouTube. 


\section{INTRODUÇÃO}

Novas formas de comunicar o escrito, especialmente através da internet, condicionaram uma relativa quebra de centenárias hierarquizações sociais da cultura letrada. Emergiram, neste contexto, outras relações de força operando de diferentes formas. Sendo a leitura "uma 'arte' que não é passividade" (CERTEAU, 2014, p. 49), o compartilhamento de experiências literárias através da web pode ser considerado não uma ruptura, mas uma continuidade neste processo de criação em uma sociedade na qual muitas das antigas barreiras entre produção e consumo foram se dissolvendo. O presente artigo analisa como isso vem se dando no YouTube, mais especificamente através do booktube.

O termo booktube designa tanto a comunidade de canais literários publicados no YouTube quando as formas de falar sobre livros adotadas por seus participantes. Em Silva (2016) é apresentada uma extensa lista de categorias de vídeos que compõem o vernáculo compartilhado pela comunidade. Dentre estas, a presente pesquisa analisa especificamente os book reviews, resenhas de livros nas quais os leitores apresentam informações factuais e, principalmente, suas percepções pessoais sobre as obras literárias que leram.

Uma vez que se pretende, neste artigo, através de vídeos da comunidade booktube, estudar as apropriações dos textos por seus leitores, serão analisadas suas confidências sobre seus protocolos de leitura, assim como seus relatos sobre os sentidos que descobrem nos textos.

\section{A LEITURA COMO PRÁTICA POLISSÊMICA}

Independente de ser erudita ou popular, toda leitura é inescapavelmente uma produção de sentidos, uma prática cultural, lugar de compreensão e de gozo que nunca é ingênua e isenta de referências exteriores a ela mesma, como explica Goulemot (2011). O texto literário é, portanto, inerentemente polissêmico. O leitor, bem como a situação de leitura são chamados por Goulemot de "fora-do-texto".

Barthes, em A Morte do Autor (2004), já questionava a possibilidade de controle dos sentidos dos textos, julgando impossível, ao autor, controlar seu significado, o qual seria sempre múltiplo. A unidade do texto se consolidaria em seu destino, e não em sua origem. Para Barthes (2004, p. 61), o texto seria "um espaço de dimensões múltiplas, onde se casam e se contestam escrituras variadas, das quais nenhuma é original". 
Na década de 60, principalmente, o leitor como indivíduo capaz de produzir sentido começa a ganhar a devida atenção, por exemplo, nos estudos da recepção. O leitor, para Umberto Eco, seria capaz e essencial para preencher as lacunas, os espaços em branco do texto. Mas não apenas isso. O leitor-modelo de Eco (1998) atualizaria os textos conforme os leria. Ele procuraria a intenção do autor e da obra, ao mesmo tempo que as testaria. Trata-se de um papel ativo e criador circunscrito pelos significados do texto. Para Eco (1988), um dos potenciais do leitor seria justamente o de reinventar o texto a partir de suas interpretações. Ao mesmo tempo que apresenta uma visão que tira o autor e o texto do centro, Eco (1993) defende os limites da interpretação pelo leitor em duas instâncias: enquanto os usos permitiriam uma interpretação limitada, esta estaria circunscrita aos limites do texto e à sua coerência. Para Eco, ter múltiplos sentidos não seria o mesmo que ter qualquer sentido. Não seria possível identificar um sentido único, correto e verdadeiro para qualquer obra, já que inerente ao sentido haveria um processo de fuga e de indeterminação. Logo, qualquer sentido que possa ser atribuído a um texto só o é em relação a um fora-do-texto, retomando Goulemot (2011) ou, para citar a visão semelhante de Certeau (2014, p. 242), “o texto [...] ordena-se conforme códigos de percepção que lhe escapam. Torna-se texto somente em relação à exterioridade do leitor, por um jogo de implicações e de astúcias". Considera-se o texto habitado pelo leitor como um "apartamento alugado", no lugar de uma busca por um sentido que Certeau (2014), ao destacar sua impossibilidade, chama de “ficção do 'tesouro' escondido na obra" ou "cofre-forte do sentido".

Aqui, considera-se que "tudo o que concerne à apresentação do texto, sua estruturação, sua distribuição dentro do volume é relevante e participa, de diferentes modos, da produção de sentido" (GONÇALVES, 2014, p. 5).

\section{A PESQUISA}

O método de pesquisa utilizado foi a análise de conteúdo, inicialmente com um detalhamento, baseado nos vídeos, de quem diz o que, como e com que efeito. Neste detalhamento foram levadas em conta uma série de informações, tais quais o perfil do interlocutor, suas motivações manifestas, a descrição de seu canal, bem como número de inscritos, origem, a duração dos vídeos, sua periodicidade e categorização. Foram detalhados os conteúdos manifestos dos vídeos, com sua transcrição e descrição de elementos visuais, 
bem como os conteúdos latentes. Para uma análise dos efeitos, foram investigadas as interações através de comentários.

Definiu-se que, para a análise da produção de sentidos, seriam abordados os vídeos do tipo book reviews, ou resenhas. Partiu-se do princípio de que "a imagem, com ou sem acompanhamento de som, oferece um registro restrito mas poderoso das ações temporais e dos acontecimentos reais - concretos, materiais" (LOIZOS, 2002, p. 137), tendo como objetivo analisar em que medida os vídeos sobre livros no YouTube podem revelar práticas de leitura polissêmicas, e que estas práticas, relatadas pela comunidade, são muito marcadas pela materialidade, aspectos estéticos, sociais e culturais dos livros impressos.

Em função de sua preponderância na comunidade booktube, foi escolhida para análise a obra The Great Gatsby (1925), de F. Scott Fitzgerald. Através da ferramenta de busca padrão do YouTube, que possui critérios próprios para ordenação de resultados, buscou-se como palavra chave o título do livro em inglês acompanhado da palavra review, separando-se três resultados que correspondessem a vídeos da comunidade booktube e que estivessem focados no conteúdo dos livros. O mesmo foi feito com os títulos traduzidos para o português, acompanhados da palavra resenha. Assim, o corpus de análise desta pesquisa é constituído por 6 vídeos transcritos em sua língua original, bem como as interações registradas nos comentários.

Foram analisadas as apropriações dos textos pelos leitores e suas práticas, aspectos estéticos dos vídeos, declarações sobre modos de ler, intenções e motivos para leitura, especificidades do texto e suas relações com tipos de leitura, a conformação material dos suportes e a psicologia do leitor.

\section{THE GREAT GATSBY NA COMUNIDADE BOOKTUBE}

A busca por "The Great Gatsby review" no YouTube trouxe 143 mil resultados ${ }^{1}$, enquanto a busca por "O Grande Gatsby resenha" apresentou 1820 vídeos. O livro, considerado por muitos um dos maiores clássicos da literatura estadunidense, tem sua leitura adotada em um grande número escolas norte-americanas. Tal fato pode ser apontado como uma das justificativas para o grande volume de conteúdo sobre The Great Gatsby no YouTube, com uma mistura de resultados sobre o livro e sobre as adaptações para o cinema.

\footnotetext{
${ }^{1}$ Coleta realizada em 22 de fevereiro de 2018.
} 
Há também muitos vídeos focados em fornecer um resumo crítico para auxiliar estudantes em seus exames, algo comum quando se trata de obras desta natureza.

Os vídeos selecionados para esta etapa da pesquisa, listados na Tabela 1, foram todos criados por booktubers e trazem em seu conteúdo suas percepções sobre a obra.

A seleção dos vídeos buscou uma certa variedade de alcance, com canais que possuem poucos inscritos, desde o Carly Lewis, com apenas 103 assinantes, até o Booksandquills, com 173 mil. Os seis vídeos foram transcritos para a análise de conteúdo, que buscou compreender o que esses booktubers têm a dizer sobre o livro em questão, e como cada um deles faz isso.

Tabela 1 - Coleta de vídeos sobre The Great Gatsby

\begin{tabular}{|c|c|c|c|c|c|}
\hline Título & Visualizações & Publicação & Duração & Canal & $\begin{array}{l}\text { Inscri } \\
\text { tos }\end{array}$ \\
\hline $\begin{array}{l}\text { Book Review | The Great } \\
\text { Gatsby by F. Scott Fitzgerald. }\end{array}$ & 36060 & $15 / \mathrm{fev} / 2014$ & $35^{\prime}$, & Booksandquills & $173 \mathrm{~K}$ \\
\hline $\begin{array}{l}\text { F. Scott Fitzgerald -- The Great } \\
\text { Gatsby: Book Review }\end{array}$ & 7760 & 23/jul/2011 & $87^{\prime} 7^{\prime}$ & Dean Goranites & $5.5 \mathrm{~K}$ \\
\hline The Great Gatsby Book Review! & 2884 & 27/jun/2016 & $12^{\prime} 40^{\prime \prime}$ & Carly Lewis & 103 \\
\hline $\begin{array}{l}\text { O GRANDE GATSBY, F. } \\
\text { SCOTT FITZGERALD }(\# 70)\end{array}$ & 12348 & $15 / a b r / 2016$ & $83^{\prime}$, & Ler Antes de Morrer & $106 \mathrm{~K}$ \\
\hline $\begin{array}{l}\text { RESENHA: O Grande Gatsby - } \\
\text { Scott Fitzgerald }\end{array}$ & 2272 & $07 / \mathrm{fev} / 2015$ & 8’09', & Resenhando Sonhos & $26 \mathrm{~K}$ \\
\hline $\begin{array}{l}\text { EU LI: O GRANDE GATSBY - } \\
\text { F. Scott Fitzgerald | All About } \\
\text { That Book } \mid\end{array}$ & 1034 & $12 / \mathrm{abr} / 2015$ & 4’40’’ & All About That Book & $32 \mathrm{~K}$ \\
\hline
\end{tabular}

Fonte: A autora, 2018.

Booksandquills é um canal em língua inglesa que está entre os mais relevantes na comunidade booktube. Ele foi criado em 2008 por Sanne Vliegenthart, uma jovem holandesa que se mudou para Londres e que trabalha no mercado editorial como social media producer na Penguin Random House UK. Seus vídeos são publicados semanalmente e têm duração variada. Sua resenha do livro The Great Gatsby foi enviada para o YouTube em fevereiro de 2014, mas na descrição do vídeo Sanne explica que ele foi publicado anteriormente em um outro canal, o qual foi desativado. Portanto, trata-se de um vídeo gravado anteriormente e republicado. No começo do vídeo a booktuber diz que se sente estranha resumindo uma obra como aquela, mas que acha necessário fazê-lo. Ela começa explicando que o livro foi escrito e ambientado nos anos 20, sendo narrado sob o ponto de vista de Nick Carraway, que se muda para Long Island, aluga uma pequena casa e se torna vizinho de um homem misterioso 
chamado Jay Gatsby. Seu resumo da obra não entra em muitos detalhes, mas algumas percepções pessoais são misturadas aos fatos descritos por ela. Por exemplo, Sanne diz que muitos dos personagens do livro não são pessoas muito agradáveis, citando o fato de que Tom Buchanam tem uma amante. Sanne interrompe a narração dos fatos, alegando que não irá adiante (para não revelar informações demais para quem não leu o livro ainda).

Ler este livro parece ser uma coisa grandiosa. Não se pode deixar de ter expectativas porque tantas pessoas disseram que este é seu livro favorito de todos os tempos. E também a história de O Grande Gatsby parece estar presente na consciência cultural coletiva. Depois de lê-lo, você saberá que você vai entender todas as piadas e todas as referências ${ }^{2}$ (BOOKSANDQUILLS, 2014).

A experiência de leitura, para Sanne, foi variada, já que ela afirma ter gostado de algumas partes e de ter se entediado em outras. Enquanto o livro é escrito com um estilo que ela descreve como "glorious writing", em algumas partes ela sentiu a necessidade de deixar o livro de lado por um tempo. A booktuber destaca que a edição que ela possui tem apenas 170 páginas, mas que ainda assim a leitura teve altos e baixos.

Uma das minhas coisas favoritas sobre a escrita, além das belas frases, foi que às vezes os momentos de ação não são realmente descritos e, em seguida, o resultado dessas ações é simplesmente afirmado como fato ${ }^{3}$ (BOOKSANDQUILLS, 2014).

Sanne conta que muitas pessoas dizem que odeiam o livro porque foram forçadas a analisá-lo na escola, mas que ela pessoalmente deseja ler a introdução de 50 páginas que pulou no começo do livro para aprender mais sobre metáforas e símbolos escondidos na obra, como a presença recorrente da cor amarela, que ela conta ter identificado. Ela afirma que em algum momento pretende relê-lo, uma vez que tende a gostar mais dos livros quando os lê uma segunda vez, sem estar preocupada em tentar descobrir o que vai acontecer na próxima página. Por fim, é interessante a afirmação que ela faz sobre a leitura de obras famosas, alegando ser difícil formar uma opinião sobre estes livros. Ao final da gravação ela recomenda alguns vídeos sobre The Great Gatsby feitos por outros canais.

\footnotetext{
${ }^{2}$ Livre tradução de: "Reading this book feels like a very big thing. You can't help but have expectations because so many people have said that this is their favorite book ever. And also the story of The Great Gatsby seems to be present in the collective cultural consciousness. Once you've read it you're in the know you'll understand all the jokes and all the references".

${ }^{3}$ Livre tradução de: "One of my favorite things about the writing except for the beautiful phrases was that sometimes moments of action weren't really described and then the result of those actions is just stated very matter-of-fact".
} 
Este vídeo específico é interessante também sob o ponto de vista estético. A gravação é feita da forma mais comum usada pela comunidade, com o booktuber posicionado em um cômodo de sua casa, diante de uma estante de livros, segurando sua edição do mesmo. Mas Sanne escolheu também se apresentar de forma diferente, usando roupa, maquiagem e acessórios que rementem à Era do Jazz nos Estados Unidos, época em que a história é ambientada.

O segundo vídeo analisado, F. Scott Fitzgerald -- The Great Gatsby: Book Review, foi publicado por Dean Goranites em julho de 2011. Seu canal, inaugurado em janeiro do mesmo ano, teve seu último vídeo publicado em 2014. Não há dados pessoais de Dean no YouTube, mas há um link para sua conta no Twitter, na qual a última interação que aparece na aba "tweets" ocorreu em 11 de agosto 2015, quando Dean comentou com um seguidor que "agora eu sinto que devo às pessoas mais vídeos" (DEANGORANITES, 2015) ${ }^{4}$. A única informação adicional disponível é que Dean mora em Los Angeles, Califórnia. No começo do vídeo analisado nesta pesquisa, o booktuber reclama do calor e enxuga o rosto com uma toalha. Em seguida, em pouco mais do que 8 minutos, Dean analisa The Great Gatsby. Ele descreve o livro como aquele que todos consideram o grande livro americano. Para ele, "o conceito de americanismo em The Great Gatsby tornou-se conectado ao livro tão intensamente que poderia ser escrito em um pedaço de papel e grampeado à capa dele ${ }^{5}$. Dean também fala sobre a onipresença da sobrecapa original do livro na mente das pessoas.

Este é um dos poucos livros que eu consigo pensar na literatura americana, em qualquer literatura para falar a verdade, onde a arte da capa ficou presa com o livro ao longo do tempo. Eu ficaria muito surpreso se você não o reconhecesse, mesmo que você nunca tenha lido este livro antes. Aquela foto azul com os olhos e a boca. A metade superior e tipo luzes da cidade ao fundo. Ninguém está realmente certo do que significa ${ }^{6}$ (DEANGORANITES, 2014).

Dean destaca no vídeo que o foco de sua resenha é a questão do sonho em The Great Gatsby. Para ele, não se trata de uma questão americana, mas universal. Nos Estados Unidos,

\footnotetext{
${ }^{4}$ Livre tradução de: "now I feel like I owe the people more videos".

${ }^{5}$ Livre tradução de: "the concept of Americanism in The Great Gatsby has become connected to the book so intensely that it might as well be written on a piece of paper and stapled to the cover of the book".

${ }^{6}$ Livre tradução de: "this is one of the few books that I can think of in American literature, in any literature really, where the cover art has stuck with the book throughout time. I'd be very surprised if you didn't recognize it even if you've never read this book before. It's that blue picture with the eyes and the mouth. The upper half and like city lights on the bottom. Nobody's really sure what it means".
} 
e no livro, o grande desejo é obter muito dinheiro. A seguir o booktuber trata de explicar o contexto socioeconômico estadunidense na década de 20, quanto muitos enriqueceram e algumas fortunas foram feitas com o contrabando de bebidas alcoólicas, algo que Dean afirma poder ser lido nas entrelinhas a respeito da fortuna de Jay Gatsby. A busca pelo sonho, segundo o booktuber, seria o diferencial do personagem em relação a todos os outros.

Em comparação com Nick Carraway, que é um homem decente, Tom Buchanan, que é irritante, Daisy, que talvez não seja tão inteligente, Gatsby aparece como esse cara do qual se quer ser amigo. Ele o chama de "esporte antigo", ele se veste bem, ele tem dinheiro, mas acho que o que é mais importante é que ele quer algo mais do que qualquer outra pessoa ao seu redor. E penso que se você olhar as pessoas que você acha atraentes, que você conhece na sua cidade, no seu campus, em torno de sua escola, as pessoas que chamam mais atenção, seja essa atenção boa ou seja má, são as pessoas que realmente querem algo, quer isso seja bom ou ruim. Eu acho que é onde Fitzgerald está tentando chegar na raiz deste romance ${ }^{7}$ (DEANGORANITES, 2014).

Diferente de Sanne, que em sua resenha apenas aponta a presença de alguns simbolismos como a cor amarela, Dean detalha mais seus exemplos, a começar pela luz verde que Gatsby enxerga ao longe. Para Dean a luz significa o desejo de alcançar algo fora de alcance, situação comum às pessoas. Seu símbolo favorito é o outdoor com os dois olhos observando a cidade, cuja simbologia é tema de debates desde que o livro foi escrito, e que Dean diz gostar de pensar que não significa nada. Para ele, seria justamente essa a mensagem do livro: "nada em nosso mundo realmente tem algum valor até que nós o coloquemos"8. Todos os leitores seriam capazes de dar infinitos significados para o livro e suas simbologias, e para Dean seria justamente esta a intenção de Fitzgerald.

Dentre os canais dos vídeos aqui analisados, o de Carly Lewis, dos Estados Unidos, é o menor, com apenas 103 assinantes. A maior parte de seus vídeos, publicados esporadicamente desde 2013, possui um pequeno número de visualizações, sendo o The Great Gatsby Book Review! o mais popular dentre suas publicações. Carly inicia sua resenha dizendo que havia acabado de ler o livro em sua turma de inglês e que está obcecada por ele.

\footnotetext{
${ }^{7}$ Livre tradução de: “. In comparison to Nick Carraway, who's a decent man, Tom Buchanan, who's annoying, Daisy, who maybe isn't that smart, Gatsby comes across as this guy that you want to be friends with. He calls you "old sport", he's dressed nice, he has money, but I think what's most important is that he wants something more than anybody else around him. And I think if you take a look at the people that you find compelling, that you know around your city, around your campus, around your high school, the people that generate the most attention, whether that attention is good or bad, are the people who really want something, whether that wanting is good or bad. I think is what Fitzgerald is trying to get to at the root of this novel.".

${ }^{8}$ Livre tradução de: "nothing in our world really has any value until we put value on it".
} 
Sua edição em paperback de capa azul é mostrada várias vezes, inclusive suas páginas de grifos e anotações.

Carly inicia sua fala com uma descrição focada naqueles que não o leram, sem fazer revelações importantes. Ela apresenta as mesmas informações dos outros vídeos: o narrador, Nick Carraway, e o contexto de Long Island, e o misterioso Gatsby, cuja casa muitos frequentam e ninguém parece conhecer. Então ela interrompe o vídeo, como se pedisse a quem não leu para fazer o mesmo, e depois segue comentando a obra em mais detalhes. Chama a atenção, neste vídeo, como a booktuber expressa mais enfaticamente seus sentimentos pelos personagens. Ela diz que ama Nick porque ver a estória através dos olhos dele deixa todos os eventos hilariantes. Para ela ele é sarcástico e invisível, sendo arrastado por todos os lados pelos outros personagens. Ela diz gostar de Daisy, uma personagem que costuma ser odiada pelos leitores. Carly ainda faz suas interpretações, inocentando a personagem.

Eu não acho que foi culpa dela que ela não tenha ido ao funeral de Gatsby. Eu sinto que foi Tom que sabia que algo aconteceu com Gatsby, porque Tom disse a Wilson que era o carro de Gatsby que atropelou Myrtle, então eu sinto que ele tentou o máximo possível manter Daisy longe disso porque sabia que se Daisy soubesse que Gatsby morreu, ela nunca mais seria a mesma $^{9}$ (CARLYLEWIS, 2016).

Carly, tendo assistindo à última adaptação cinematográfica da história, diz ter especialmente gostado do fato de o filme mostrar outros pontos de vista além do de Nick, único narrador do livro, deixando mais claro que outros eventos podem ter ocorrido sem que ele soubesse. Ela insiste que teria sido culpa de Tom o fato de Daisy não ter comparecido ao funeral.

Ao falar de Jay Gatsby, Carly mistura percepções que teve do livro com percepções do filme. Ela também apresenta alguns pontos de vista singulares. Por exemplo, afirma gostar do fato de que não se trata apenas de uma história de amor, mas de uma história de amizade entre Nick e Gatsby. Em seguida, Carly desenvolve o que ela alega ser sua teoria sobre Nick, mencionando uma cena em que Nick está no elevador com outro personagem.

Se você sabe do que estou falando, ou se não sabe, é uma cena na festa de Myrtle, nas páginas 37 e 38, e aí já fica a dica, mas talvez Nick não seja

\footnotetext{
${ }^{9}$ Livre tradução de: “I don't think it was her fault that she didn't go to Gatsby's funeral. I feel like it was Tom that knew something happened to Gatsby because Tom did told Wilson that it was Gatsby's car that ran over Myrtle, so I feel like he tried as hard as possible to keep Daisy away from that because he knew that if she knew that Gatsby died he would never be the same".
} 
heterossexual. Mas eu acho que ele tinha mais do que sentimentos de amizade por Gatsby. Eu também sinto que ele ama muito Gatsby ${ }^{10}$ (CARLYLEWIS, 2016).

As três resenhas analisadas apresentam visões distintas que de certa forma se complementam, mas que demonstram como pequenos detalhes na obra são interpretados de forma diferente e ganham diferentes níveis de importância.

Parte-se, então, para uma análise de três vídeos em língua portuguesa, buscando compreender como alguns deles apresentam e interpretam o livro. O canal brasileiro Ler Antes de Morrer, criado por Isabella Lubrano, também possui um vídeo sobre Gatsby. Com mais de 150 mil inscritos, trata-se de um dos maiores canais de booktube em língua portuguesa, com mais de 300 vídeos publicados desde 2014, quando foi criado. A booktuber se apresenta como jornalista formada pela USP e pela Cásper Líbero, e explica no canal que seu objetivo é resenhar 1001 livros. O vídeo O GRANDE GATSBY, F. SCOTT FITZGERALD (\#70), publicado em 5 de fevereiro de 2015, foge um pouco aos padrões dos demais pois não é gravado em um ambiente fechado diante de uma estante de livros. Isabella grava todo o conteúdo de sua resenha no que ela descreve como "uma das vistas mais conhecidas do planeta" (LERANTESDEMORRER, 2016). Do alto do observatório do World Trade One, arranha-céu construído no local onde ficavam as Torres Gêmeas em Nova York, Isabella mostra Manhattan do alto e aponta para Long Island, descrevendo-a como uma espécie de Alphaville para os moradores de São Paulo. Ela segue apresentando aos leitores a região metropolitana de Nova York, vista do alto, e explica que o local onde está gravando fica na parte sul da cidade, sendo também a região em que o narrador de $O$ Grande Gatsby, Nick Carraway, trabalhava.

Os nossos personagens em $\mathrm{O}$ Grande Gatsby circulam entre Long Island, que é uma área residencial, e a ilha de Manhattan, que era já desde a década de XX do século passado o centro financeiro do mundo. E agora tá vendo esse monte de prédios bem aqui do lado? A gente está no sul da ilha de Manhattan em uma região conhecida como o distrito financeiro. É a região que é o centro. A capital mundial do capitalismo e é aqui que trabalhava o narrador de $\mathrm{O}$ Grande Gatsby, um cara chamado Nick Carraway, que não é o protagonista, mas ele é um personagem muito importante. Ele trabalhava aqui nessa mesma região, principalmente na região de Wall Street, que é a rua principal das financeiras, dos bancos, da bolsa de valores. Aqui é que circula o dinheiro, e olha, é muito dinheiro desde os anos 20 do século

\footnotetext{
${ }^{10}$ Livre tradução de: "If you know what I'm talking about or if you don't, it's the one at Myrtle's party and on page 37 and 38 and that kind of gives you the hint, but maybe Nick's not straight. But I do think that he had more than friendly feelings for a Gatsby. I feel like he was kind of in love with Gatsby too".
} 
passado. E esse Nick Carraway, ele é quem nos conta a história (LERANTESDEMORRER, 2016).

Isabella não revela muito sobre os principais eventos do livro, nem menciona a simbologia presente na história. Ela apresenta os principais personagens, Nick, Gatsby e Daisy, e trata de contextualizar a história. Isabella fala do sonho americano, do self made man, personificado em Gatsby. “A história de amor dele com a Daisy, essa obsessão que ele tem por essa menina, esse desejo de possuir inclusive o amor do passado, vai ter consequências muito impressionantes e na verdade muito trágicas" (LERANTESDEMORRER, 2016). Para Isabella, mais do que uma história de amor, o livro é crítico e pessimista, mas fácil de ler. Ela termina a resenha mostrando a edição brasileira da Penguin, elogiando-a, sugerindo que sua compra através do link seria uma forma de apoiar financeiramente seu canal.

O canal de Tamirez Santos, Resenhando Sonhos, foi criado em 2014 e possui pouco mais de 25 mil assinantes. O vídeo RESENHA: O Grande Gatsby - Scott Fitzgerald, publicado em 2015, faz parte de um projeto dela de ler mais livros que ela chama de clássicos, sendo esta a primeira tentativa. Ela começa a resenha contando sua experiência de leitura: “por não ser familiarizada com os anos 20 , que é onde acontece a história, então pra mim foi bem difícil" (RESENHANDOSONHOS, 2015). Ela revela ter sentido falta de descrições dos lugares, de como as pessoas se vestem e de onde moram. De uma forma bastante coloquial a booktuber revela em linhas gerais a história e apresenta os personagens, falando sobre como foi importante ter assistido à última adaptação para o cinema, que permitiu a ela visualizar cenários e eventos que ela teve dificuldade em compreender.

Eu fiquei feliz em ter feito essa leitura. Acho que comecei por um livro bom, porque apesar de ter sido complicado de eu ter seguido em frente, não foi um livro que eu li com que eu vi as páginas passar de forma leve, foi um livro que foi pesado pra mim porque foi a minha primeira leitura clássica, digamos assim (RESENHANDO SONHOS, 2015).

O vídeo é um relato interessante de uma leitora jovem, acostumada com livros mais comerciais, tendo o primeiro contato com obras que ela considera clássicas. Tamirez lê dois trechos do livro para demonstrar "o quanto o livro é denso". Ela sugere que seus inscritos façam como ela: que leiam o livro sem desistir, e em seguida assistam ao filme, já que para ela a adaptação cinematográfica foi essencial para a compreensão da obra.

Como ocorreu em alguns dos vídeos analisados anteriormente, Tamirez mostrou algumas vezes o livro impresso, uma edição bilíngue que tem como capa uma imagem do filme com Leonardo DiCaprio. 
O último vídeo que compõe essa análise é de mais uma leitora que, no canal All About that book, criado em 2015 por Mayra, habitualmente fala de obras mais voltadas para o público jovem adulto. Em EU LI: O GRANDE GATSBY - F. Scott Fitzgerald, Mayra demonstra certa frustração com a experiência. Ela inicia o vídeo descrevendo a história, em linhas gerais, e os principais personagens. Para a booktuber o estilo de escrita de Fitzgerald é interessante, o que a leva a ter curiosidade de ler outras obras do autor, mas este seria o único ponto positivo. Ela critica os personagens, especialmente Gatsby.

O cara de tudo quanto é jeito, da forma mais obscura possível, vai levantar uma fortuna pra quê? Porque ele acha que a mulher dos sonhos dele, com quem não fala faz cinco anos, que já é casada, já tem uma filha, só vai dar atenção para ele se ele for rico. E aí em vez de ir falar com ela, escrever uma carta, visitar... não, que que ele faz? Ele faz um monte de festas caríssimas e esdrúxulas para quem saiba talvez ela vá na festa e aí eles vão se reencontrar. Toda a visão que ele tem da Daisy é totalmente deturpada, idealizada, e aí ele acha a forma mais babaca possível de reconquistar ela. Então pra mim foi difícil ler um livro em que você despreza todos os personagens e que o texto em si não está criticando esse comportamento (ALLABOUTTHATBOOK, 2015)

A booktuber não traz nenhuma outra informação além dos elementos iniciais do plot, e menciona brevemente que percebe que Fitzgerald tentou trazer no livro algum tipo de comentário sobre o american way of life, o que para ela não foi suficiente para tornar o livro interessante. Diferente dos outros booktubers nos vídeos anteriormente analisados, que gostaram da obra, Mayra expõe claramente sua opinião sobre $O$ Grande Gatsby e termina o vídeo dizendo esperar não ter ofendido as pessoas que gostam dele. O livro em suas mãos é uma edição em inglês da Penguin, parte de uma coleção das obras de Fitzgerald com sobrecapas com temas art deco.

Parte-se agora para uma análise complementar que busca nos espaços públicos de interação dos vídeos as mensagens trocadas sobre eles pelos espectadores. Aqueles que assistem aos vídeos podem interagir de duas formas principais: clicando no botão de gostei ou não gostei, e deixando comentários. Através da coleta destes comentários pretende-se também realizar uma análise de seus conteúdos para tentar compreender como eles se relacionam aos vídeos e de que maneira oferecem relatos de leitura e interpretações pessoais para a produção de sentidos do livro em questão.

Na coleta e análise de todos os 274 comentários publicados nestes 6 vídeos, percebe-se que eles não diferem muito dos tipos principais de interação realizada através do YouTube, e 
que, no caso dos vídeos que constituíram o corpus de análise desta pesquisa, na maioria das vezes os comentários não foram respondidos pelo booktuber.

Aqueles que publicam vídeos no YouTube têm a opção de clicar no botão de like do comentário realizado, o que indica que o mesmo foi lido por ele. No entanto, o YouTube não disponibiliza a outra pessoa, senão ao booktuber e ao autor do comentário, saber quem marcou o botão de like. Portanto não é possível utilizar a presença dessas marcações como indício de que os comentários foram ao menos visualizados pelo booktuber, a não ser que ele marque o botão em forma de coração, que graficamente se destaca na área de comentários publicamente. Esta funcionalidade foi disponibilizada pelo YouTube apenas em 2016, o que explica o fato de quase não aparecer nos comentários analisados.

Não é possível estabelecer qualquer tipo de categorização para esta coleção de interações presentes nos vídeos sobre The Great Gatsby, mas nota-se que os comentários no qual o usuário compartilha sua própria opinião e experiência de leitura são frequentes. Buscou-se observar mais atentamente justamente estes comentários que ofereciam ou uma experiência pessoal de leitura ou uma interpretação sobre a obra e, ao mesmo tempo, comentários diretamente relacionados a algo falado ou mostrado no vídeo. Os comentários abaixo, feitos em diferentes datas por diferentes usuários no vídeo do canal Booksandquilss, são exemplos de como se dá essa interação. No primeiro caso tem-se um relato de um leitor que teve contato com a obra no passado e que sempre teve a percepção de que havia perdido algo importante durante a leitura, já que de repente foi surpreendido com acontecimentos relatados de forma muito sucinta e direta pelo autor, algo comentado pela booktuber em seu vídeo. No segundo comentário destacado a seguir, um usuário se apresenta como um professor de inglês que lê a obra em voz alta duas vezes por ano, e que concorda com o que a booktuber fala sobre Fitzgerald citar acontecimentos surpreendentes como se não tivessem importância. O comentário ainda menciona o contraste sobre a brevidade da descrição destes eventos, ao passo que detalhes sobre o sorriso de Gatsby são descritos recorrentemente. Em um terceiro comentário a insatisfação com a obra é destacada, principalmente apontando os personagens como causa para o livro não ser interessante.

Eu não leio Gatsby desde o ginásio, mas o "de repente alguém morreu" estilo de escrita realmente chamou minha atenção. Eu sempre achei que tinha lido errado porque eu senti que tinha perdido muita coisa, mas já que você teve a mesma experiência, talvez eu não seja estúpida! Certo? CERTO!? 
Como um professor de inglês que lê "The Great Gatsby" em voz alta duas vezes por ano, eu definitivamente concordo que Fitzgerald torna eventos mais emocionantes como: assassinato, suicídio e acidentes automobilísticos tão monótonos e sem graça quanto possível. No entanto, ele dedica linha após linha à descrição do sorriso de Gatsby.

Minha impressão foi: "Uau, essa história é super chata", e depois de entrar na história e nos personagens, foi: "Uau, Gatsby é um garoto de 15 anos perto da Daisy". Eu percebi o comentário social, mas a história foi retardada. Os idiotas elogiam este livro por todos os motivos errados. Se os personagens são burros, então o livro é burro. E Jay Gatsby é um personagem pobre, e quem se importa com Nick Carroway (sic), francamente? ${ }^{11}$

Também chamam a atenção comentários de leitores que oferecem dicas aos booktubers, referindo-se a práticas que auxiliam a leitura, como, por exemplo, realizar uma pesquisa sobre a época e o lugar em que a obra é ambientada. Um dos comentários nos vídeos do canal Resenhando Sonhos destaca isso.

Esse livro já está na lista! Uma dica: Quando for ler livros que não esteja familiarizada com a época, tema e costumes ou que não tenha filme, pesquise antes no google o local onde a história se passa e a data... Por exemplo, O Grande Gatsby: década de 20 em Nova Iorque. Eu pesquiso sobre veículos, casas, roupas. Funciona comigo :).

Nos comentários dos vídeos analisados também foram encontrados posicionamentos e interpretações que se opõem aos dos booktubers. No vídeo do canal All about that book, no qual Mayra critica o livro e se diz decepcionada com o mesmo e com sua mensagem, ela é contrariada por alguns usuários, que oferecem uma perspectiva diferente, enquanto outros afirmam que ela não entendeu o livro.

$\mathrm{O}$ autor em momento nenhum glorifica o comportamento da sociedade americana na época, até porque o narrador da história não é o próprio autor e sim o Nick, que desde a primeira página se mostra uma pessoa muito

\footnotetext{
${ }^{11}$ Livre tradução de: "I haven't read Gatsby since high school, but the "suddenly someone is dead" type of writing really stood out to me. I always assumed I had read it wrong because I felt like I missed a lot, but since you had the same experience MAYBE I'M NOT STUPID! Right? RIGHT!?
}

As an English teacher who reads "The Great Gatsby" out loud twice a year I definitely agree that Fitzgerald makes more exciting events like: murder, suicide, and auto accidents as dull and uneventful as possible. Yet, he must dedicate line after line describing Gatsby's smile.

My impression was, "Wow, this story is super boring," and then after getting into the story and the characters, it was, "Wow, Gatsby is a 15-year old boy around Daisy." I get the social commentary, but the story was retarded. Idiots praise this book for all the wrong reasons. If the characters are dumb, then the book is dumb. And Jay Gatsby is a poor character, and who cares about Nick Carroway, frankly?." 


\begin{abstract}
imparcial com os outros e fala que busca nunca criticar ninguém. Não achei uma glorificação da ganância, o final foi um tapa na cara, mostrou a desgraça e infelicidade que ela pode nos levar, e criticou (sutilmente, deixando o leitor ter suas próprias reflexões) o egoísmo daqueles personagens. Fiquei surpresa por você ter achado a história vazia, não sei se foi o momento da leitura, mas essa história falou muito comigo sobre não depositar a sua Felicidade no dinheiro ou no amor de outra pessoa. Sem falar em um personagem que eu achei sensacional, o Nick, que no meio de pessoas que não conseguem pensar em nada além delas mesmas e não conseguem suportar uma provocação ou uma situação desagradável sem brigar, ele permanece muito respeitoso com os outros por mais que o que a pessoa fez vá muito além dos princípios dele.
\end{abstract}

Pode-se dizer que a seção de comentários dos vídeos é a principal forma de interação entre o booktuber e seus assinantes, ou entre pessoas que de forma aleatória assistiram aos vídeos e decidiram registrar seus pontos de vista. É desta forma que o booktuber consegue saber a opinião das pessoas sobre o livro em questão e principalmente sobre o conteúdo do vídeo.

É interessante notar que, dentre os 274 comentários, apenas 29 foram feitos pelos booktubers em resposta às mensagens deixadas pelas pessoas que visualizaram os vídeos. Dentro da pequena amostra definida por esta pesquisa, pode-se afirmar que booktubers com canais com menor número de comentários tendem a respondê-los com mais frequência, enquanto, no caso dos canais com mais de 100 mil assinantes, a resposta direta a um comentário é mais rara. Isso coloca em questão o quão interativo é o YouTube como plataforma de interação entre leitores. Por exemplo, o vídeo Book Review | The Great Gatsby by F. Scott Fitzgerald, do canal Booksandquills, foi visualizado 36.060 vezes, recebeu 938 likes e 12 dislikes. Ainda que se considere que as mesmas pessoas possam ter visualizado o vídeo diversas vezes, trata-se de um percentual de interação relativamente baixo, com 67 comentários de usuários e apenas 1 da booktuber em questão.

Não se pode utilizar estes números como referência para uma generalização no que diz respeito à interação na comunidade booktube como um todo, mas a coleta de dados revela, sobre os conteúdos analisados, que os vídeos são muito mais visualizados do que comentados, e que o espaço dos comentários não se mostra uma via de mão dupla que suscite discussões aprofundadas sobre a obra. Por outro lado, os comentários que indicam interesse pela leitura do livro foram recorrentes, o que pode ser indício de que aqueles que visualizam este tipo de vídeo buscam mais recomendações de leitura do que um espaço para debate literário. 


\section{CONSIDERAÇÕES}

Retoma-se aqui algumas questões essenciais. A primeira delas é que a leitura dos textos comportados por um livro seria de fato o momento principal ao se pensar seus usos e apropriações, mas não se pode ignorar que o papel dos agentes humanos é muito mais amplo quando se considera a produção e circulação de objetos textuais (GONÇALVES, 2010). Os canais que se inserem no contexto da comunidade booktube, fazem parte destas etapas de produção e circulação de objetos textuais de diversas formas.

Desta análise, alguns pontos merecem destaque. O conteúdo manifesto dos vídeos, através de seu registro e leitura cuidadosa, demonstra como um breve resumo da obra sempre está presente nos vídeos de resenha, mas nem sempre é o principal conteúdo compartilhado. Alguns vídeos oferecem mais do que uma simples descrição e uma opinião curta. Enquanto alguns compartilham experiências pessoais de leitura, outros demonstram conhecer bem a obra e as peculiaridades que fazem dela o que é. O fato de The Great Gatsby contar com uma adaptação cinematográfica relativamente recente também é relevante, uma vez que o filme foi evocado por alguns booktubers como referência e fonte de parte de sua compreensão sobre a obra de Fitzgerald, ainda que alguns reconheçam que há tanto semelhanças quanto diferenças. Os vídeos relatam a busca pessoal, pelo leitor, do sentido, mas ao mesmo tempo ilustram como este é apresentado de forma diferente por cada indivíduo. Ele se transforma na gravação do vídeo e depois, nas trocas de comentários. A produção de sentidos, portanto, não é estanque, mas marcada pela fuga e pela indeterminação de um sentido que jamais é único. Ela é influenciada pela obra em si, mas também por tudo aquilo que a cerca, pelo leitor, pelos aspectos materiais do livro, que vez ou outra são mencionados pelos booktubers ao falarem das edições através das quais os textos foram lidos, especialmente suas capas.

Considera-se também que, ao se investigar os caminhos dos livros impressos no contemporâneo, entram em jogo todos os processos que são englobados pela expressão "produção de sentidos". A própria conformação material dos textos seria carregada de sentidos e, nos usos e apropriações, engendraria diferentes expectativas e valores culturais, como foi observado nos vídeos aqui analisados.

A comunidade booktube se insere na plataforma do YouTube e, portanto, influencia e é influenciada pelas práticas de seus milhões de usuários, bem como pelas ferramentas e modos de operação programados pelo próprio sistema. 
A presente pesquisa visou justificar a premissa de que a polissemia do sentido está relacionada a todo texto, especialmente o literário. Trata-se aqui, da impossibilidade de um sentido único a qualquer obra e das apropriações de textos por seus leitores. A pesquisa demonstrou os modos como os booktubers falam sobre livros e, consequentemente, se apropriam de seu conteúdo em seus vídeos.

\section{REFERÊNCIAS}

ALLABOUTTHATBOOK. EU LI: O GRANDE GATSBY - F. Scott Fitzgerald | All About That

Book. Disponível em: 〈https://www.youtube.com/watch?v=ruHraUgpErs〉. Acesso em 22 fev 2018.

BARTHES, Roland. A Morte do Autor. In: O Rumor da Língua. São Paulo: Martins Fontes, 2004.

BAUER, M. W.; AARTS, B. A construção do corpus: um princípio para a coleta de dados qualitativos. IN: BAUER, M. W \& GASKELL, G. Pesquisa Qualitativa Com Texto, Imagem e Som: um Manual Prático. Vozes, 2008. pp. 39-63.

BOOKSANDQUILLS, 2014. Book Review | The Great Gatsby by F. Scott Fitzgerald. Disponível em: < https://www.youtube.com/watch?v=34NVSoo4y88>. Acesso em 22 fev 2018.

CARLYLEWIS, 2016. The Great Gatsby Book Review! Disponível em: < https://www.youtube.com/watch?v=RqbF8VF9wzk>. Acesso em 3 mar 2018.

CERTEAU, Michel de. A invenção do cotidiano: 1. Artes de fazer. 22. Ed. Petrópolis: Vozes, 2014.

DEANGORANITES, 2011. F. Scott Fitzgerald -- The Great Gatsby: Book Review. Disponível em: < https://www.youtube.com/watch?v=2E0TtuxMfVk >. Acesso em 1 mar 2018.

ECO, Umberto. Interpretação e superinterpretação. São Paulo: Martins Fontes, 1993.

. Lector in fabula. São Paulo: Perspectiva, 1988.

1988.

Obra aberta. Forma e indeterminação nas poéticas contemporâneas. São Paulo: Perspectiva,

GONÇALVES, Márcio Souza. Materialidade, meio de comunicação, culturas e agentes humanos. Anais do XXIII Encontro Nacional dos Programas de Pós-Graduação em Comunicação. 2014. Disponível em:

<http://compos.org.br/encontro2014/anais/Docs/GT03_COMUNICACAO_E_CULTURA/compos201 4-materialidademeiosdecomunicacaoculturaseagenteshumanos_2154.pdf>. Acesso em: 12 mai 2015.

GOULEMOT, Jean Marie. Da leitura como produção de sentidos. CHARTIER, R (org.). Práticas de leitura. Trad. Cristiane Nascimento. 5. Ed. São Paulo: Estação Liberdade, 2011.

LERANTESDEMORRER. 2016. O GRANDE GATSBY, F. SCOTT FITZGERALD (\#70). Disponível em: < https://www.youtube.com/watch?v=DP_fGdgTBDo>. Acesso em 22 fev 2018. 
LOIZOS, Peter. Vídeo, filme e fotografias como documentos de pesquisa. IN: BAUER, Martin W \&

GASKELL, George. Pesquisa Qualitativa Com Texto, Imagem e Som: um Manual Prático. Vozes, 2008. pp. 137-155.

RESENHANDOSONHOS. RESENHA: O Grande Gatsby - Scott Fitzgerald. Disponível em: < https://www.youtube.com/watch?v=uVCcsZDMfCM >. Acesso em 22 fev 2018.

SILVA, Renata Prado Alves. Booktube: livros e leitura em vlogs no YouTube. In: INTERCOM, 39, 2016. Anais do XXXIX Congresso Brasileiro de Ciências da Comunicação. São Paulo: Intercom, 2016.

Original recebido em: 22 maio 2020

Aceito para publicação em: 22 outubro 2020

Renata Prado Alves Silva

Professora no Centro Universitário Estácio Juiz de Fora, onde ministra as disciplinas Mídias Digitais, Arquitetura da Informação, Design Editorial, Semiótica Aplicada ao Design, Fundamentos de Design e Computação Gráfica nos cursos de Jornalismo, Publicidade e Propaganda, Design Gráfico e Design de Moda. Foi coordenadora, de 2013 a 2019, do Núcleo de Comunicação (NUCOM), um laboratório de produção multimídia. Anteriormente coordenou os cursos de Publicidade e Propaganda

e Jornalismo da Estácio. Atuou com Comunicação, Editoração e Design de Conteúdo na Centralx entre 2004 e 2012. Criou e coordenou a Revista Eletrônica da Faculdade Metodista Granbery, onde também atuou como Jornalista. Possui graduação em Comunicação Social pela Universidade Federal de Juiz de Fora (2004) e MBA em Marketing pela Faculdade de Administração e Economia da Universidade Federal de Juiz de Fora (2006). Mestre pelo Programa de Pós-Graduação da Faculdade de Comunicação da Universidade Federal de Juiz de Fora (2010) e Doutora em Comunicação (2018) na Universidade do Estado do Rio de Janeiro, linha de pesquisa Tecnologias de Comunicação e Cultura.

\author{
(@) $\odot \Theta \odot$ \\ Esta obra está licenciada com uma Licença \\ Creative Commons Atribuição-NãoComercial-CompartilhaIgual 4.0 Internacional
}

